\title{
3-month and 12-month mortality after first liver transplant in adults in Europe: predictive models for outcome
}

\begin{abstract}
Andrew K Burroughs, Caroline A Sabin, Keith Rolles, Valerie Delvart, Vincent Karam, John Buckels, John G O'Grady, Denis Castaing, Jurgen Klempnauer, Neville Jamieson, Peter Neuhaus, Jan Lerut, Jean de Ville de Goyet, Stephen Pollard, Mauro Salizzoni, Xavier Rogiers, Ferdinand Muhlbacher, Juan Carlos Garcia Valdecasas, Christopher Broelsch, Daniel Jaeck, Joaquin Berenguer, Enrique Moreno Gonzalez, Rene Adam, on behalf of the European Liver Transplant Association*
\end{abstract}

\section{Summary}

Background Mortality after liver transplantation depends on heterogeneous recipient and donor factors. Our aim was to assess risk of death and to develop models to help predict mortality after liver transplantation.

Methods We analysed data from 34664 first adult liver transplants from the European Liver Transplant Registry to identify factors associated with mortality at 3-months ( $\mathrm{n}=21605$ in training dataset) and 12-months ( $\mathrm{n}=18852$ in training dataset) after transplantation. We used multivariable logistic regression models to generate mortality scores for each individual, and assessed model discrimination and calibration on an independent validation datase ( $n=9489$ for 3-month model and $n=8313$ for 12-month model).

Findings 2540 of 21605 (12\%) individuals in the 3-month training sample had died by 3 months. Compared with those transplanted in 2000-03, those transplanted earlier had a higher risk of death. Increased mortality at 3-months post-transplantation was associated with acute liver failure (adjusted odds ratio 1.61), donor age older than 60 years $(1 \cdot 16)$, compatible $(1 \cdot 22)$ or incompatible $(2 \cdot 07)$ donor-recipient blood group, older recipient age

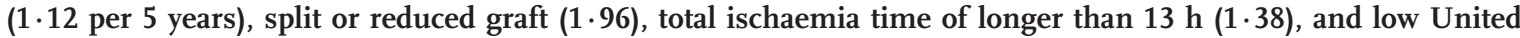
Network for Organ Sharing score (score 1: 2.43; score 2: 1.67). However, cirrhosis with hepatocellular carcinoma, alcohol cirrhosis, hepatitis $\mathrm{C}$ or primary biliary cirrhosis, donor age 40 years or younger, or less, hepatitis $\mathrm{B}$, and larger size of transplant centre ( $\geqslant 70$ transplants per year) were associated with improved early outcomes. The 3-month mortality score discriminated well between those who did and did not die in the validation sample (C statistic=0.688). We noted similar findings for 12-month mortality, although deaths were generally underestimated at this timepoint.

Interpretation The 3-month and 12-month mortality models can be effectively used to assess outcomes both within and between centres. Furthermore, the models provide a means of assessing the risk of post-transplantation mortality, giving clinicians important data on which to base strategic decisions about transplant policy in particular individuals or groups.

\section{Introduction}

The measurement of surgical outcomes, especially in cardiac surgery, has been extensively researched. ${ }^{1}$ In liver transplantation, several models have been used to identify factors associated with outcomes. ${ }^{2-6}$ However, most models are based on data from a single centre; thus their results cannot confidently be extrapolated to other populations of individuals receiving transplants. ${ }^{7}$ Furthermore, the models are restricted to an assessment of survival at 12 months after transplantation. Although mortality at 12 months reflects surgical mortality, it also captures mortality associated with recurrent disease, chronic rejection, and retransplantation. Mortality rates at timepoints earlier than 12 months predominantly include surgical mortality, however, and could be associated with different factors to those linked to mortality at 1 year.

Data from the European Liver Transplant Registry (ELTR) have been used to establish the intrinsic mortality risk associated with liver transplantation without identified risk factors; ${ }^{8}$ the results of the study by Adam and colleagues suggest that every centre could assess its own performance by combining this risk with the quoted relative risk ratios of known risk factors However, the approach used to estimate the risk ratios (proportional hazards regression) does not provide absolute expected mortality rates, thereby limiting the practical application of these results. Furthermore, the results were based on transplants undertaken up to December, 1997. As survival continues to improve after liver transplantation, these models need to be updated.

Our aim, therefore, was to assess 3-month and 12 -month mortality after first liver transplantation in a cohort of adult recipients from the ELTR who had transplants up to 2003.

\section{Methods \\ Population}

The ELTR database contains information about all liver transplants done in 23 European countries since 1968. The methods used to obtain the data and details of the data collected have been described previously, ${ }^{8}$ and
Lancet 2006; 367: 225-32

*Participants listed at end of report

Liver Transplantation and Hepatobiliary Medicine, Royal Free Hampstead NHS Trust, London NW3 2QG, UK (Prof A K Burroughs FRCP, K Rolles FR(S); Department of Primary Care and Population Sciences, Royal Free and University College Medical School, London, UK (Prof C A Sabin PhD); Hôpital Paul Brousse, Villejuif, Paris France (V Delvart PhD,

V Karam PhD,

Prof D Castaing MD, Prof R Adam MD); Queen Elizabeth Hospital, Birmingham, UK (J Buckels FRCS); King's College Hospital, London, UK

(J G O'Grady FRCPI); Medizinische Hochschule Hannover, Hannover, Germany (Prof J Klempnauer MD); Addenbrooke's Hospital Cambridge, UK (N Jamieson FRCS); Charité-Universitätsklinikum zu Berlin, Berlin, Germany (Prof P Neuhaus MD); Cliniques Universitaires Saint-Luc, Brussels, Belgium (Prof) Lerut MD Prof J de Ville de Goyet MD); St James' and Seacroft University Hospital, Leeds, UK (S Pollard FRCS); Centro de Trapianti di Fegato, Torino, Italy (Prof M Salizzoni MD); Universitätskrankenhaus Eppendorf, Hamburg, Germany (Prof X Rogiers MD); Klinishe Abteilung für Transplantation, Wien Austria (Prof F Muhlbacher MD); Hospital Clinic I Provincial de Barcelona, Barcelona, Spain (Prof) C Garcia Valdecasas MD); CUK GHs Essen, Essen,

Germany (Prof C Broelsch MD), Hôpital Hautepierre, Strasbourg, France (D Jaeck MD); Hospital Universitario La Fe, Valencia, Spain (J Berenguer MD); and Hospital 12 de Octubre, Madrid, Spain (Prof E M Gonzalez MD)

Correspondence to: Prof Andrew Burroughs, Liver Transplantation and Hepatobiliary Medicine, Royal Free Hampstead NHS Trust, London NW3 2QG, UK andrew.burroughs@royalfree. nhs.uk 
Panel: Calculation of 3-month and 12-month mortality scores

Consider, for example, a male recipient of a liver transplant done in $\mathbf{2 0 0 0}$ with the following characteristics: acute liver failure, donor age 27 years, donor-recipient blood group compatible, recipient HBV negative, recipient aged 52 years, received a full graft, UNOS status 1 , total ischaemia time $6.4 \mathrm{~h}$, transplanted in a centre that did 91 transplants in the same year. The 3-month mortality score would be calculated as:

$-3.38$

+0.48 (acute liver failure)

-0.21 (donor aged $\leqslant 40$ years)

$+0 \cdot 20$ (donor-recipient blood group compatible)

$+(0.113[52-40] / 5)$ (recipient aged 52 years)

+0.89 (UNOS status 1 )

-0.23 (centre did $\geqslant 70$ transplants in year)

giving a 3-month mortality score of -1.986 .

The exponential (e) of $-1 \cdot 98=0 \cdot 137$. Thus, the estimated probability that this individual will die within 3-months is calculated as:

$0.137 /(1+0.137)=0.12(12 \%)$

results of an audit ${ }^{10}$ published in 2003 confirm the validity of the data. Data are submitted anonymously by either national transplant registries (UK, Spain) or by individual centres. Here, we present analyses based on data from transplants done in adults between Jan 1, 1988, and June 30, 2003.

The ELTR does not obtain individual consent from patients for inclusion of their data, since the French National ethics committee (Commission Nationale de L'Informatique et des Libertés)—which was consulted because the ELTR is based in Paris-considered it unnecessary. All data are anonymised.

\section{Procedures and statistical analysis}

We identified factors independently associated with 3-month and 12-month mortality with multivariable logistic regression models. Each dataset was randomly split into a training set (about $70 \%$ of transplants) used to generate the model, and a validation set (about 30\% of transplants) for assessing the model's adequacy of fit. We used the training set to identify factors independently associated with mortality, using a backwards selection procedure.

Factors considered were: year of transplantation, disease cause (acute liver failure, hepatocellular carcinoma, alcoholic cirrhosis, hepatitis $\mathrm{C}$ virus [HCV] cirrhosis, primary biliary cirrhosis, other), recipient sex and age, donor sex and age, United Network of Organ Sharing (UNOS) status of recipient (1=intensive care unit bound, $2=$ continuous hospitalisation, $3=$ continuous medical care, $4=$ at home with normal function), recipient's HCV antibody status (note that these patients might have had other primary causes for their cirrhosis), and hepatitis B virus (HBV) surface antigen (HbsAG) status, donor and recipient $\mathrm{ABO}$ blood groups and matching status (identical, compatible, incompatible, not known), bypass type (extracorporal, lateral clamping, none, not known), graft type (full, split or reduced, unknown), total ischaemia time, and size of the transplant centre. We initially divided donor and recipient age into 10-year age groups. However, after identifying factors associated with mortality, we examined the adjusted odds ratios associated with each age group to assess if combining categories was appropriate to simplify the model. As a result, donor age was recategorised into three groups $(\leqslant 40,41-60$, and $>60$ years) for both final models. The odds ratios associated with each recipient age group increased progressively with increasing age. As such, we used recipient age as a continuous variable in the final model. Total ischaemia time was initially divided into eight groups based on percentiles. After fitting the final models, only a total ischaemia time greater than $13 \mathrm{~h}$ conferred a significant increase in the odds of mortality. Centre size was based on the number of transplants done in every transplant year, changing over time as centres did more or less transplants in a year. We also stratified centre size into eight groups based on percentiles; we assessed adjusted odds ratios to test the appropriateness of combining any groups. As a result, we reclassified centres as doing less than 37 (small), 37-69 (medium), or 70 or more (large) transplants yearly. We did not adjust models by country in accord with agreed ELTR policy; predicted rates therefore indicate average mortality rates expected over Europe.

We used the parameter estimates from the final models (the logarithms of the adjusted odds ratios) to derive scores for every individual for use in estimating the probability of death over the 3-months or 12-months post-transplantation. The score is calculated by multiplying the appropriate parameter estimates shown in table 2 by the corresponding covariate values for each individual (see panel for example). This mortality score can then be used to give an estimate of the probability of that individual dying within 3 months of transplantation, using the following equation:

$$
\text { Probability }=\frac{E^{\text {score }}}{\left(1+E^{\text {score }}\right)}
$$

where $\mathrm{e}^{\text {score }}$ represents the exponential of the score. A risk calculator for the calculation of predicted mortality probabilities ( $95 \% \mathrm{CI})$ is available from authors.

We tested the adequacy of the models in three ways. First, we compared the scores of those who had or had not died with unpaired $t$ tests. Second, we calculated the discriminative ability of the model with Harrell's C index. ${ }^{11}$ Third, to assess the calibration of the models, 
we stratified patients according to the deciles of the distribution of their mortality scores, and compared observed and expected numbers of deaths in each group with the Hosmer-Lemeshow statistic. ${ }^{12}$ Because the fit of any model is always better on the dataset used to generate the model than on the general population, we also calculated these statistics for the validation set to give unbiased estimates of model adequacy. We did all analyses with SAS, version 8.02.

\section{Role of the funding source}

The sponsors of the study had no role in study design, data collection, data analysis, data interpretation, or writing of the report. The corresponding author had full access to all the data in the study and had final responsibility for the decision to submit for publication.

\section{Results}

Table 1 shows patients' characteristics. 52386 transplants were done between Jan 1, 1988, and June 30, 2003. Of these, we excluded the data for the following: 6977 retransplants; 5146 transplants done in children younger than age 15 years; 848 combined organ transplants; and 55 transplants with no follow-up information. A further 4696 transplants had missing information on the key data items: recipient sex $(n=13)$, donor sex $(n=4119)$, and donor age $(n=3984)$. The missing data were associated primarily with earlier transplants (missing data: 27\% [1988-1991], 21\% [1992-1995], 5\% [1996-1999], and 5\% [2000-2003]) and were primarily due to the progressive addition of new data items to the ELTR questionnaire. ${ }^{10} \mathrm{We}$ therefore assessed data for 34664 first liver transplants in adults. Our assessment of 3-month mortality is based on 31094 transplants, since we excluded 552 individuals transplanted after April 1, 2003 (who did not have the potential for 3 months of follow-up) and 3018 individuals who were not known to have died but whose follow-up was less than 3 months. The assessment of 12-month mortality is based on 27165 transplants, excluding 2858 individuals transplanted after June 30, 2002 (who did not have the potential for 12 months of follow-up) and 4641 individuals whose follow-up was less than 12 months.

For the 3-month model, we included 21605 of 31094 individuals (69\%) in the training sample, of whom 2540 (12\%) had died by 3 months post-transplantation (table 1). Table 2 shows results from the multivariable model for outcomes at 3 months. Compared with the most recently transplanted cohort of 2000-03, those who received transplants in earlier periods were at a higher risk of death $(\mathrm{p}<0 \cdot 0001)$. After adjustment for the period of transplant, an increased risk of mortality at 3-months post-transplantation was associated with acute liver failure, donor age older than 60 years, compatible or mismatched donor-recipient blood groups, older recipient age, poor clinical status (lower
UNOS scores), the receipt of a split or reduced graft, and total ischaemia time of longer than $13 \mathrm{~h}$. By

\begin{tabular}{|c|c|c|c|c|}
\hline & \multicolumn{2}{|c|}{ 3-month mortality } & \multicolumn{2}{|c|}{ 12-month mortality } \\
\hline & Number (\%) & $\begin{array}{l}\text { Number (\%) dead } \\
\text { in } 3 \text { months }\end{array}$ & Number (\%) & $\begin{array}{l}\text { Number (\%) dead } \\
\text { in } 12 \text { months }\end{array}$ \\
\hline \multicolumn{5}{|l|}{ Transplant information } \\
\hline Patients in training sample & $21605(100 \%)$ & $2540(12 \%)$ & $18852(100 \%)$ & $3391(18 \%)$ \\
\hline \multicolumn{5}{|l|}{ Year of transplant } \\
\hline 1988-1991 & $2526(12 \%)$ & $444(18 \%)$ & $2446(13 \%)$ & $607(25 \%)$ \\
\hline 1992-1995 & $4859(22 \%)$ & $604(12 \%)$ & $4678(25 \%)$ & $884(19 \%)$ \\
\hline 1996-1999 & $7735(36 \%)$ & $829(11 \%)$ & $7478(40 \%)$ & $1195(16 \%)$ \\
\hline $2000-2003$ & $6485(30 \%)$ & $663(10 \%)$ & $4250(23 \%)$ & $705(17 \%)$ \\
\hline \multicolumn{5}{|l|}{$\begin{array}{l}\text { Number of transplants done } \\
\text { by centre in year of transplant }\end{array}$} \\
\hline$\leqslant 20$ & $2795(13 \%)$ & $436(16 \%)$ & $2492(13 \%)$ & $577(23 \%)$ \\
\hline $21-28$ & $2536(12 \%)$ & $339(13 \%)$ & $2293(12 \%)$ & $426(19 \%)$ \\
\hline $29-36$ & $2573(12 \%)$ & $338(13 \%)$ & $2214(12 \%)$ & $458(21 \%)$ \\
\hline $37-45$ & $3004(14 \%)$ & $340(11 \%)$ & $2661(14 \%)$ & $453(17 \%)$ \\
\hline $46-54$ & $2736(13 \%)$ & $284(10 \%)$ & $2398(13 \%)$ & $408(17 \%)$ \\
\hline $55-69$ & $2555(12 \%)$ & $235(9 \%)$ & $2161(11 \%)$ & $337(16 \%)$ \\
\hline $70-100$ & $2727(13 \%)$ & $284(10 \%)$ & $2237(12 \%)$ & $391(17 \%)$ \\
\hline$>100$ & $2679(12 \%)$ & $264(10 \%)$ & $2396(13 \%)$ & $341(14 \%)$ \\
\hline \multicolumn{5}{|l|}{ Recipient information } \\
\hline \multicolumn{5}{|l|}{ Cause of liver failure } \\
\hline Acute liver failure & $1917(9 \%)$ & $529(28 \%)$ & $1672(9 \%)$ & $548(33 \%)$ \\
\hline Hepatocellular carcinoma & $2248(10 \%)$ & $209(9 \%)$ & $1946(10 \%)$ & $398(20 \%)$ \\
\hline Alcoholic cirrhosis & $4652(22 \%)$ & $453(10 \%)$ & $4102(22 \%)$ & $586(14 \%)$ \\
\hline HCV cirrhosis & $3668(17 \%)$ & $371(10 \%)$ & $3240(17 \%)$ & $562(17 \%)$ \\
\hline Primary biliary cirrhosis & $1833(8 \%)$ & $171(9 \%)$ & $1602(8 \%)$ & $227(14 \%)$ \\
\hline Other & $7287(34 \%)$ & $807(11 \%)$ & $6290(33 \%)$ & $1070(17 \%)$ \\
\hline \multicolumn{5}{|l|}{ Sex } \\
\hline Male & $13510(63 \%)$ & $1494(11 \%)$ & $11745(62 \%)$ & 2037 (17\%) \\
\hline Female & $8095(37 \%)$ & $1046(13 \%)$ & $7107(38 \%)$ & $1354(19 \%)$ \\
\hline \multicolumn{5}{|l|}{ Age (years) } \\
\hline$\leqslant 20$ & $598(3 \%)$ & $73(12 \%)$ & $517(3 \%)$ & $78(15 \%)$ \\
\hline $21-30$ & $1330(6 \%)$ & $165(12 \%)$ & $1118(6 \%)$ & $186(17 \%)$ \\
\hline $31-40$ & $2794(13 \%)$ & $294(11 \%)$ & $2476(13 \%)$ & $355(14 \%)$ \\
\hline $41-50$ & $5802(27 \%)$ & $657(11 \%)$ & $5120(27 \%)$ & $857(17 \%)$ \\
\hline $51-60$ & $7784(36 \%)$ & $937(12 \%)$ & $6747(36 \%)$ & $1288(19 \%)$ \\
\hline $61-70$ & $3245(15 \%)$ & $407(13 \%)$ & $2835(15 \%)$ & $619(22 \%)$ \\
\hline$>70$ & $52(<1 \%)$ & $7(13 \%)$ & $39(<1 \%)$ & $8(21 \%)$ \\
\hline \multicolumn{5}{|l|}{ UNOS status } \\
\hline 1 & $2570(12 \%)$ & $684(27 \%)$ & $2246(12 \%)$ & $745(33 \%)$ \\
\hline 2 & $1636(8 \%)$ & $248(15 \%)$ & $1350(7 \%)$ & $300(22 \%)$ \\
\hline 3 & $6830(32 \%)$ & $667(10 \%)$ & $5842(31 \%)$ & $951(16 \%)$ \\
\hline 4 & $4998(23 \%)$ & $326(7 \%)$ & $4259(23 \%)$ & $502(12 \%)$ \\
\hline Unknown & $5571(26 \%)$ & $615(11 \%)$ & $5155(27 \%)$ & $893(17 \%)$ \\
\hline Anti-HCV positive & $5298(28 \%)^{*}$ & $514(10 \%)$ & $4672(28 \%)^{*}$ & $809(17 \%)$ \\
\hline HBsAg positive & $2722(13 \%)^{*}$ & $281(10 \%)$ & $2370(13 \%)^{*}$ & $394(17 \%)$ \\
\hline \multicolumn{5}{|l|}{ Donor information } \\
\hline \multicolumn{5}{|l|}{ Sex } \\
\hline Male & $13357(62 \%)$ & $1554(12 \%)$ & $11656(62 \%)$ & $2068(18 \%)$ \\
\hline Female & $8248(38 \%)$ & $986(12 \%)$ & $7196(38 \%)$ & $1323(18 \%)$ \\
\hline \multicolumn{5}{|l|}{ Age (years) } \\
\hline$\leqslant 10$ & $172(1 \%)$ & $21(12 \%)$ & $158(1 \%)$ & $32(20 \%)$ \\
\hline $11-20$ & $3261(15 \%)$ & $361(11 \%)$ & $2965(16 \%)$ & $475(16 \%)$ \\
\hline $21-30$ & $4067(19 \%)$ & $443(11 \%)$ & 3659 (19\%) & $592(16 \%)$ \\
\hline $31-40$ & $3741(17 \%)$ & $438(12 \%)$ & $3297(17 \%)$ & $568(17 \%)$ \\
\hline $41-50$ & $4300(20 \%)$ & $529(12 \%)$ & $3939(21 \%)$ & $713(18 \%)$ \\
\hline $51-60$ & $3573(17 \%)$ & $446(12 \%)$ & $3003(16 \%)$ & $594(20 \%)$ \\
\hline $61-70$ & $1888(9 \%)$ & $232(12 \%)$ & $1543(8 \%)$ & $311(20 \%)$ \\
\hline$>70$ & $603(3 \%)$ & $70(12 \%)$ & $490(3 \%)$ & $106(22 \%)$ \\
\hline \multicolumn{5}{|l|}{ Donor-recipient $\mathrm{ABO}$ group } \\
\hline Identical & $19877(92 \%)$ & $2189(11 \%)$ & $17338(92 \%)$ & $2980(17 \%)$ \\
\hline Compatible & $1450(7 \%)$ & $279(19 \%)$ & $1275(7 \%)$ & $319(25 \%)$ \\
\hline Incompatible & $182(1 \%)$ & $56(31 \%)$ & $157(1 \%)$ & $68(43 \%)$ \\
\hline Not known & $96(<1 \%)$ & $16(17 \%)$ & $82(<1 \%)$ & $24(29 \%)$ \\
\hline
\end{tabular}




\begin{tabular}{|c|c|c|c|c|}
\hline \multicolumn{5}{|l|}{ (continued) } \\
\hline \multicolumn{5}{|c|}{ Transplant information } \\
\hline \multicolumn{5}{|l|}{ Bypass type } \\
\hline Extracorporeal & 5948 (28\%) & 792 (13\%) & $5437(29 \%)$ & $1059(19 \%)$ \\
\hline Lateral clamping & $4919(23 \%)$ & $514(10 \%)$ & $4157(22 \%)$ & $712(17 \%)$ \\
\hline None & $8738(40 \%)$ & $944(11 \%)$ & $7599(40 \%)$ & $1290(17 \%)$ \\
\hline Unknown & $2000(9 \%)$ & $290(15 \%)$ & $1659(9 \%)$ & $330(20 \%)$ \\
\hline \multicolumn{5}{|l|}{ Graft type } \\
\hline Full & $20116(93 \%)$ & $2273(11 \%)$ & $17597(93 \%)$ & $3100(18 \%)$ \\
\hline Split or reduced & $997(5 \%)$ & $174(17 \%)$ & $764(4 \%)$ & $171(22 \%)$ \\
\hline Unknown & $492(2 \%)$ & $93(19 \%)$ & $491(3 \%)$ & $120(24 \%)$ \\
\hline \multicolumn{5}{|c|}{ Total ischaemia time (h) } \\
\hline$\leqslant 5 \cdot 0$ & $2814(13 \%)$ & $281(10 \%)$ & $2461(13 \%)$ & $404(16 \%)$ \\
\hline$>5 \cdot 0-6 \cdot 2$ & $2287(11 \%)$ & $232(10 \%)$ & $1980(11 \%)$ & $324(16 \%)$ \\
\hline$>6 \cdot 2-7 \cdot 5$ & $2791(13 \%)$ & $288(10 \%)$ & $2364(13 \%)$ & $405(17 \%)$ \\
\hline$>7 \cdot 5-8.6$ & $2226(10 \%)$ & $251(11 \%)$ & $1936(10 \%)$ & $306(16 \%)$ \\
\hline$>8.6-9.9$ & $2407(11 \%)$ & $268(11 \%)$ & $2089(11 \%)$ & $344(16 \%)$ \\
\hline$>9 \cdot 9-11 \cdot 3$ & $2753(13 \%)$ & $314(11 \%)$ & $2337(12 \%)$ & $426(18 \%)$ \\
\hline$>11 \cdot 3-13 \cdot 0$ & $2489(12 \%)$ & $278(11 \%)$ & $2197(12 \%)$ & $389(18 \%)$ \\
\hline$>13 \cdot 0$ & $2454(11 \%)$ & $345(14 \%)$ & $2204(12 \%)$ & $452(21 \%)$ \\
\hline Unknown & $1384(6 \%)$ & $283(20 \%)$ & $1284(7 \%)$ & $341(27 \%)$ \\
\hline \multicolumn{5}{|c|}{$\begin{array}{l}\text { Anti-HCV status available for } 19216 \text { patients at } 3 \text { months and } 16670 \text { patients at } 12 \text { months. HBsAg status available for } \\
20250 \text { patients at } 3 \text { months and } 17664 \text { patients at } 12 \text { months. Proportions of deaths in age groups refer to total per group }\end{array}$} \\
\hline
\end{tabular}

contrast, cirrhosis with a hepatocellular carcinoma, high alcoholic cirrhosis, HCV or primary biliary cirrhosis, donor age of younger than 40 years, $\mathrm{HBsAg}$ positivity, and larger size of centre were all associated with a better 3-month outcome in multivariable analyses.

We used the estimates from the multivariable logistic regression model to generate a 3-month predictive score for every individual in the training sample (mean [SD] score $-2 \cdot 19[0 \cdot 67])$. In those who had died within 3 months, the mean (SD) score was $-1.75(0.76)$ compared with $-2 \cdot 24(0.63)$ in those who remained alive at 3 months $(\mathrm{p}=0.0001$, unpaired $t$ test). The C statistic from this model was 0.691 , indicating a reasonable ability of the score to discriminate between those who died and those who remained alive at 3-months post-transplantation. We stratified patients according to the deciles of the distribution of scores; table 3 shows the expected and observed number of deaths within each stratum. The Hosmer-Lemeshow statistic was $8.94(p=0 \cdot 35)$, suggesting no evidence of lack of fit. When the same predictive score was calculated for the 9489 patients in the validation sample (mean $-2.20[0 \cdot 66]$ ), we noted similar results. In particular, the $\mathrm{C}$ statistic was 0.688 and the HosmerLemeshow test was not significant, indicating a similar level of performance to that seen with the training sample.

With respect to the 12 -month model, we included 18852 of 27165 individuals (69\%) in the training sample, of whom 3391 (18\%) had died by 12 months (table 1). Results from the multivariable model for 12-month outcomes (table 2) were very similar to those for 3-month outcomes. The mean [SD] predicted mortality score in the training sample was $-1 \cdot 63(0 \cdot 61)$ $(-1 \cdot 32[0 \cdot 65]$ in those who had died and $-1 \cdot 70[0 \cdot 58]$ in those still alive at 12 months post-transplantation). The model C statistic was 0.667 and the Hosmer-Lemeshow test statistic was $2 \cdot 70(\mathrm{p}=0 \cdot 95)$. However, by contrast with the 3-month results, when we calculated the score for the 8313 individuals in the validation sample, the Hosmer-Lemeshow test gave a significant result $(\mathrm{p}=0 \cdot 002)$, suggesting that the 12-month score lacked calibration. Examination of the observed and expected number of deaths in each stratum suggested that the 12-month predictive score generally underestimated the risk of mortality in this sample, although its discriminative ability remained good.

Table 4 shows the causes of death in those dying at 3-months and at 12-months after transplantation. Although the number of deaths was higher at 12 months, the relative proportions of individuals dying from each cause were broadly similar with the exceptions of non-tumoural liver disease recurrence and tumours, which both arose with a higher frequency over the first year than over the first 3 months.

\section{Discussion}

We used a large European dataset to identify the main risk factors for 3-month and 12-month mortality in adults undergoing a first liver transplantation. The large size of the ELTR database as well as its representativeness mean that it is a powerful tool for developing and assessing predictive models for outcome after liver transplantation. The models we have generated can be used to assess the likelihood of early mortality in a patient about to undergo transplantation by considering recipient characteristics and potential donor and transplant-related characteristics. The models can also be used by centres to assess their past performance and compare it with the performance of other European centres over a similar period.

We included transplants done from 1988 onwards. We chose this date because it corresponds to the standardisation of liver transplantation across Europe and the by then widespread use of cyclosporin-based immunosuppression, which resulted in improved surgical outcomes.? However, even after excluding any transplants done before this date, 3-month and 12 -month mortality rates have continued to improve over time. ${ }^{9,13}$

Acute liver failure was associated with an increased risk of mortality at both timepoints, consistent with the results of previous analyses of this dataset ${ }^{8}$ and other studies. ${ }^{14,15}$ Compared with other causes, individuals who needed a transplant because of cirrhosis with hepatocellular carcinoma, alcoholic cirrhosis, HCV cirrhosis, or primary biliary cirrhosis generally had a reduced risk of mortality, especially at 3-months posttransplantation. As before, non-identical blood groups 
and a longer total ischaemia time were significantly associated with a poorer prognosis. ${ }^{8}$ In general, nonmatched donors are likely to be used when the need for transplant is urgent. However, the effects of a nonidentical blood group remained significant after adjustment for other factors in the model, including acute liver failure and UNOS status, suggesting that these findings are not fully explained by a poorer clinical status at the time of transplantation. We also noted that total ischaemia time in excess of $13 \mathrm{~h}$ was a risk factor for mortality (previous analyses identified a cutoff of $12 \mathrm{~h}^{8}$ ). Although the precise threshold for ischaemia time is unclear, attempts to reduce total ischaemia times below $12 \mathrm{~h}$ are likely to improve outcomes.

One of the advantages of the models presented is that they could be used to estimate an individual's risk of mortality under different transplant conditions. Thus, the risk of mortality after a transplant with a nonmatched donor can be weighed against the risk of mortality if the transplant is delayed until a matched donor can be found. Similarly, the benefits of introducing methods to reduce total ischaemia timeeg, by operating throughout the night—can be balanced against the possible risks of this clinical scenario. ${ }^{16,17}$

As in the previous report ${ }^{18}$ that presented results from an analysis of the data from the ELTR, split or reduced liver transplants were associated with a poor outcome. The split or reduced liver transplant category included transplants from living donors; unfortunately, because of the small number of such transplants (only $2 \%$ of all transplants) we could not separate the relative contributions of each factor to survival. However, since transplants from living donors are increasing in frequency, further analysis of this cohort will soon be possible.

The accuracy of a predictive model will always seem to be unduly high if it is assessed on the same dataset used to generate the model; thus models should be validated on data from an external source. ${ }^{19}$ Although we have not validated this model on data from a different source, the large size of the ELTR dataset allowed subdivision into training and validation samples. Both models generated had good discriminative ability, indicating that those with higher scores were more likely to die over both the short-term and the longterm. Whereas the 3-month model was also well calibrated, the 12-month model showed a tendency to underestimate mortality rates by around $10 \%$. This finding is not surprising-while preoperative factors are likely to be the strongest predictors of death in the first few months after transplant, post-operative factors could start to play a more important part over the longer-term. For example, changes in renal function over follow-up, and severity and frequency of cellular rejection could all contribute to mortality over the longer-term. Our analyses, which are based on

\begin{tabular}{|c|c|c|c|c|}
\hline & \multicolumn{2}{|c|}{ 3-month mortality } & \multicolumn{2}{|c|}{ 12-month mortality* } \\
\hline & Estimate & Odds ratio $(95 \% \mathrm{Cl})$ & Estimate & Odds ratio $(95 \% \mathrm{Cl})$ \\
\hline Intercept $†$ & .. & -3.38 & .. & -2.94 \\
\hline \multicolumn{5}{|l|}{ Year of transplant } \\
\hline 1988-1991 & 0.62 & $1.86(1.60-2.16)$ & 0.61 & $1.84(1.60-2.11)$ \\
\hline $1992-1995$ & 0.22 & $1.25(1.10-1.41)$ & 0.23 & $1.26(1.12-1.42)$ \\
\hline 1996-1999 & 0.08 & $1.08(0.97-1.21)$ & 0.00 & $1.00(0.90-1.12)$ \\
\hline $2000-2003$ & \multicolumn{4}{|l|}{ Reference } \\
\hline \multicolumn{5}{|l|}{ Cause of liver failure } \\
\hline Acute liver failure & 0.48 & $1.61(1.34-1.93)$ & 0.27 & $1.30(1.09-1.56)$ \\
\hline Hepatocellular carcinoma & -0.29 & $0.75(0.63-0.88)$ & 0.09 & $1.09(0.95-1.25)$ \\
\hline Alcoholic cirrhosis & $-0 \cdot 26$ & $0.77(0.68-0.88)$ & -0.33 & $0.72(0.64-0.81)$ \\
\hline HCV cirrhosis & $-0 \cdot 20$ & $0.82(0.71-0.94)$ & -0.09 & $0.91(0.81-1.03)$ \\
\hline Primary biliary cirrhosis & -0.52 & $0.59(0.49-0.71)$ & -0.57 & $0.56(0.48-0.67)$ \\
\hline Other & \multicolumn{4}{|l|}{ Reference } \\
\hline \multicolumn{5}{|l|}{ Age of donor (years) } \\
\hline$\leqslant 40$ & -0.21 & $0.81(0.74-0.89)$ & -0.27 & $0.76(0.70-0.83)$ \\
\hline $41-60$ & \multicolumn{4}{|l|}{ Reference } \\
\hline$>60$ & 0.15 & $1.16(0.99-1.36)$ & 0.19 & $1.21(1.06-1.37)$ \\
\hline \multicolumn{5}{|l|}{ Donor-recipient $A B O$ groups } \\
\hline Identical & \multicolumn{4}{|l|}{ Reference } \\
\hline Compatible & 0.20 & $1.22(1.05-1.42)$ & 0.14 & $1.15(1.00-1.33)$ \\
\hline Incompatible & 0.73 & $2.07(1.47-2.91)$ & 0.91 & $2.47(1.76-3.48)$ \\
\hline HBsAg positive & -0.38 & $0.68(0.59-0.79)$ & -0.28 & $0.76(0.67-0.86)$ \\
\hline $\begin{array}{l}\text { Recipient age } \\
\text { (per } 5 \text { years older) } \dagger\end{array}$ & 0.11 & $1.12(1.10-1 \cdot 14)$ & 0.13 & $1.14(1.12-1.16)$ \\
\hline Split or reduced graft & 0.67 & $1.96(1.61-2 \cdot 35)$ & 0.45 & $1.57(1.30-1.89)$ \\
\hline \multicolumn{5}{|l|}{ UNOS status } \\
\hline 1 & 0.89 & $2.43(2.07-2.85)$ & 0.85 & $2 \cdot 33(2.00-2 \cdot 71)$ \\
\hline 2 & 0.51 & $1.67(1.43-1.94)$ & 0.43 & $1.54(1.34-1.78)$ \\
\hline 3 & \multicolumn{4}{|l|}{ Reference } \\
\hline 4 & -0.43 & $0.65(0.57-0.74)$ & -0.35 & $0.71(0.63-0.79)$ \\
\hline \multicolumn{5}{|l|}{ Total ischaemia time $(\mathrm{h})$} \\
\hline$\leqslant 13$ & \multicolumn{4}{|l|}{ Reference } \\
\hline$>13$ & 0.32 & $1.38(1.21-1.57)$ & 0.24 & $1.27(1.13-1.43)$ \\
\hline Unknown & 0.67 & $1.95(1.68-2 \cdot 27)$ & 0.52 & $1.67(1.46-1.92)$ \\
\hline \multicolumn{5}{|c|}{ Size of centre (transplants per year) } \\
\hline$\leqslant 36$ & 0.30 & $1.36(1.23-1 \cdot 50)$ & $0 \cdot 19$ & $1.22(1.10-1 \cdot 34)$ \\
\hline $37-69$ & \multicolumn{4}{|l|}{ Reference } \\
\hline$\geqslant 70$ & -0.23 & $0.80(0.71-0.90)$ & -0.21 & $0.81(0.73-0.90)$ \\
\hline \multicolumn{5}{|c|}{$\begin{array}{l}\text { *All variables significant at } 0.0001 \text { level. } † \text { Results of model scaled so that intercept relates to a transplant recipient } \\
\text { aged } 40 \text { years and odds ratios indicate effect of a } 5 \text {-year increase in age. When estimating mortality score for an individual, } \\
\text { subtract } 40 \text { years from score and divide by } 5 \text { before entering covariate in model. }\end{array}$} \\
\hline \multicolumn{5}{|c|}{$\begin{array}{l}\text { Table 2: Results from multivariable logistic regression model of factors associated with mortality at } \\
\text { 3-months and at 12-months post-transplantation }\end{array}$} \\
\hline
\end{tabular}

preoperative factors only, will not capture these factors. Furthermore, over time patients increasingly become at risk of other, non-transplant-related causes of death. Thus, although the model will be especially useful for stratifying patients according to their risk of death over 12 months, absolute estimates of risk should be interpreted with caution.

Several limitations of the database should be acknowledged. First, only the details obtained as part of the ELTR registry could be studied. Neither recipient renal function, nor recipient ventilation before liver transplantation are recorded in the database, and markers of liver status-eg, Pugh's score or MELD (model for endstage liver disease) - are not available. Although these factors might contribute to the increased mortality risk, their overall importance is likely to be subsumed by other factors, such as UNOS 


\begin{tabular}{|c|c|c|c|c|c|c|}
\hline & \multicolumn{3}{|c|}{ Training sample } & \multicolumn{3}{|c|}{ Validation sample } \\
\hline & $\begin{array}{l}\text { Number of } \\
\text { patients }\end{array}$ & $\begin{array}{l}\text { Number of deaths } \\
\text { expected }\end{array}$ & $\begin{array}{l}\text { Number of deaths } \\
\text { observed }\end{array}$ & $\begin{array}{l}\text { Number of } \\
\text { patients }\end{array}$ & $\begin{array}{l}\text { Number of deaths } \\
\text { expected }\end{array}$ & $\begin{array}{l}\text { Number of deaths } \\
\text { observed }\end{array}$ \\
\hline \multicolumn{7}{|l|}{3 months } \\
\hline 1 & 2161 & $88 \cdot 4$ & 78 & 949 & 38.6 & 41 \\
\hline 2 & 2161 & $120 \cdot 0$ & 104 & 948 & $52 \cdot 3$ & 60 \\
\hline 3 & 2159 & $143 \cdot 1$ & 137 & 950 & $62 \cdot 3$ & 65 \\
\hline 4 & 2165 & $165 \cdot 2$ & 184 & 948 & $71 \cdot 2$ & 78 \\
\hline 5 & 2157 & $187 \cdot 8$ & 201 & 949 & $82 \cdot 2$ & 91 \\
\hline 6 & 2160 & $215 \cdot 5$ & 217 & 949 & $94 \cdot 1$ & 89 \\
\hline 7 & 2161 & 251.8 & 265 & 949 & $109 \cdot 4$ & 122 \\
\hline 8 & 2160 & 303.6 & 289 & 949 & $131 \cdot 7$ & 138 \\
\hline 9 & 2161 & $396 \cdot 4$ & 402 & 949 & $170 \cdot 0$ & 169 \\
\hline 10 & 2160 & $669 \cdot 2$ & 663 & 949 & $293 \cdot 2$ & 285 \\
\hline Total & 21605 & 2541 & 2540 & 9489 & $1105 \cdot 1$ & 1138 \\
\hline Hosmer-Lemeshow statistic* &.. &.. & $8.94(p=0.35)$ &.. &.. & $5.87(p=0.83)$ \\
\hline C statistic &.. & .. & 0.691 & .. &.. & 0.688 \\
\hline \multicolumn{7}{|l|}{12 months } \\
\hline 1 & 1884 & $132 \cdot 6$ & 123 & 831 & $57 \cdot 9$ & 57 \\
\hline 2 & 1886 & $181 \cdot 4$ & 181 & 831 & $79 \cdot 1$ & 102 \\
\hline 3 & 1886 & $215 \cdot 6$ & 217 & 832 & $93 \cdot 7$ & 105 \\
\hline 4 & 1887 & $247 \cdot 4$ & 241 & 831 & $107 \cdot 6$ & 126 \\
\hline 5 & 1881 & $278 \cdot 7$ & 295 & 831 & $122 \cdot 3$ & 138 \\
\hline 6 & 1888 & $316 \cdot 8$ & 312 & 832 & 138.9 & 145 \\
\hline 7 & 1885 & $360 \cdot 0$ & 370 & 831 & $157 \cdot 8$ & 187 \\
\hline 8 & 1885 & $415 \cdot 6$ & 412 & 832 & $183 \cdot 4$ & 197 \\
\hline 9 & 1885 & $503 \cdot 2$ & 490 & 831 & $220 \cdot 6$ & 234 \\
\hline 10 & 1885 & $739 \cdot 8$ & 750 & 831 & $323 \cdot 5$ & 349 \\
\hline Total & 18852 & $3391 \cdot 1$ & 3391 & 8313 & $1484 \cdot 8$ & 1640 \\
\hline Hosmer-Lemeshow statistic* &.. &.. & $2.70(p=0.95)$ & .. &.. & $27.54(p=0.002)$ \\
\hline C statistic &.. & .. & 0.667 & .. & .. & 0.662 \\
\hline
\end{tabular}

status. Furthermore, the MELD score is primarily used for the assessment of allocation and eligibility for transplantation, and, since it does not take into account operative or donor factors, it is a poor predictor of posttransplantation survival. ${ }^{20,21}$ Second, we excluded patients with missing data on key data items, such as

\begin{tabular}{lcc|}
\hline & 3-months post-transplantation & 12-months post-transplantation* \\
\hline Intraoperative death & $264(7 \%)$ & $252(5 \%)$ \\
\hline Infection & $1002(27 \%)$ & $1295(26 \%)$ \\
Liver complications or rejection & $97(3 \%)$ & $191(4 \%)$ \\
\hline Technical complications & $279(8 \%)$ & $327(6 \%)$ \\
Primary non-function or dysfunction & $229(6 \%)$ & $219(4 \%)$ \\
Non-tumoral recurrence & $20(1 \%)$ & $178(4 \%)$ \\
Other liver complication & $75(2 \%)$ & $97(2 \%)$ \\
Gastrointestinal causes & $108(3 \%)$ & $131(3 \%)$ \\
Cardiovascular causes & $291(8 \%)$ & $344(7 \%)$ \\
Cerebrovascular causes & $260(7 \%)$ & $310(6 \%)$ \\
Other organ failure (renal, & $401(11 \%)$ & $503(10 \%)$ \\
pulmonary, bone marrow, & & \\
multiple organ) & $33(1 \%)$ & $407(8 \%)$ \\
Tumours & $408(11 \%)$ & $492(10 \%)$ \\
Other causes & $211(6 \%)$ & $285(6 \%)$ \\
Unknown & $3678(100 \%)$ & $5031(100 \%)$ \\
Total & \\
Data are number (\%). *Deaths at 12 months exclude any deaths occurring in individuals transplanted after June 30, 2002, in line \\
with the analytical method; thus not all deaths at 3-months post-transplantation are included in the 12-month column. \\
\hline Table 4: Causes of death at 3-months and at 12-months post-transplantation
\end{tabular}

recipient sex and donor age and sex, as well as those with insufficient follow-up to assess outcomes at 3-months and 12-months post-transplantation. The former group of patients was largely restricted to transplants done in earlier time periods, and their exclusion should not, therefore, adversely effect the results from the more recently done transplants. By contrast, however, those with insufficient follow-up tended to be individuals who were transplanted, as expected, in 2002-03. Finally, some variability in the characteristics of patients undergoing transplantation in the different European countries included in this registry is likely. According to ELTR policy, we have not adjusted for country; our results thus indicate the average effect of each factor on mortality across Europe.

The 3-month and 12-month mortality prognostic indices we have investigated can be used to assess outcomes both within and between centres, using the most recently transplanted patients in the ELTR (2000-03) as the reference cohort. Furthermore, the models provide a means of assessing the risk of posttransplant mortality, according to potential donor characteristics, ${ }^{22}$ thus giving clinicians important data on which to base strategic decisions about transplant policy in particular individuals or groups. ${ }^{12}$ 


\section{Contributors}

A K Burroughs was the main investigator and conceived the study together with K Rolles. C A Sabin did the statistical analyses. R Adam, V Delvart, and V Karam contributed to the report with their knowledge of the ELTR database and experience of a previous ELTR publication on part of the same dataset. A K Burroughs and C Sabin drafted the report and all authors then contributed to subsequent drafts. All other authors listed contributed patients to the database, and commented on and approved the final version of the manuscript.

\section{Conflict of interest statement}

We declare that we have no conflict of interest.

\section{Participants of the European Liver Transplant Association (ELTA)}

Addenbrooke's Hospital, Cambridge, UK-N Jamieson;

Centro de Trapianti di Fegato, Torino, Italy-M Salizzoni;

Centro Trapianti di Fegato, Bari, Italy_V Memeo; Charité-

Universitätsklinikum zu Berlin, Berlin, Germany_P Neuhaus;

Children's Memorial Health Institute, Warsaw, Poland-P Kalicinski; Chirurgische Universitätsklinik und Poliklinik, Würzburg, GermanyW Timmermann; C H Princesse Grace, Monte-Carlo, MonacoC Huguet; C H U de Caen, Caen, France-P Segol; C H U de Grenoble, Grenoble, France (C Letoublon ; $\mathrm{C} \mathrm{H} \mathrm{U} \mathrm{de} \mathrm{Liège,} \mathrm{Liège,}$ Belgium-M Meurisse; C H U Nancy, Vandoeuvre, France-P Boissel; C H U Vaudois, Lausanne, Switzerland-M Gillet; C H U Necker, Paris, France-Y Revillon, F Lacaille; Clinica Puerto de Hierro, Madrid, Spain-J Ardaiz; Clinica Universitaria de Navarra, Pamplona, SpainJ A Cienfuegos; Cliniques Universitaires Saint-Luc, Brussels, Belgium-J Lerut, J de Ville de Goyet; C S U de Bellvitge, Barcelona, Spain-E Jaurrieta; C T U K Munchen, Munchen, GermanyM Stangl; C U K Freiburg, Freiburg, Germany—G Kirste; C U K GHs Essen, Essen, Germany-C Broelsch; C U K Innsbruck, Innsbruck, Austria-R Margreiter; Dijkzigt Hospital, Rotterdam, NetherlandsS W Schalm; Eberhard-Karls-Universität Tubingen, Tubingen, Germany-R Viebahn; Freeman Hospital, Newcastle-upon-Tyne, UKD M Manas; Friedrich Schiller Universität Jena, Jena, GermanyJ Scheele; Georg August Universität Göttingen, Göttingen, GermanyH Becker; Hôpital des enfants, Toulouse, France-P Broue; Hôpital de la Conception, Marseille, France-Y P Letreut; Hôpital de Pontchaillou, Rennes, France-J P Campion, K Boudjema; Hôpital Erasme, Brussels, Belgium-M Gélin; Hôpital Rangueil, Toulouse France-G Fourtanier; Hôpital Hautepierre, Strasbourg, FranceD Jaeck, P Wolf; Hôpital Jean Minjoz, Besancon, France-G Mantion; Hôpital Dupuytren, Limoges, France-B Descottes; Hôpital Beaujon, Clichy, France-J Belghiti; Hôpital Calmette, Lille, FranceF R Pruvot; Hôpital Cantonal Universitaire de Genève, Geneva, Switzerland-P Morel, G Mentha; Hôpital Cochin, Paris, FranceD Houssin; Hôpital de la Croix-Rousse, Lyon, France-C Ducerf; Hôpital du Kremlin-Bicêtre, Le Kremlin-Bicêtre, France-F Gauthier; Hôpital E Herriot, Lyon, France-O Boillot; Hôpital G\&R Laénnec, Nantes, France-J Visset; Hôpital Henri Mondor, Créteil , FranceD Cherqui; Hôpital KBC Dedinje, Beograd, Yugoslavia-B Radevic; Hôpital de la Timone Enfants, Marseille, France-A Delarue; Hôpital Pasteur Nice, Nice, France-A Bourgeon; Hôpital Paul Brousse, Villejuif, France-D Castaing; Hôpital Pitié-Salpétrière, Paris, France-L Hannoun; Hôpital Saint Antoine, Paris, France-R Parc; Hôpital Saint-Eloi, Montpellier, France-I Domergue; Hôpital Sain Roch, Nice, France-J Guggenheim; Hôpital Tripode, Bordeaux, France-J Saric; Hospitais da Universidade de Coimbra, Coimbra, Portugal—D L Furtado; Hospital 12 de Octubre, Madrid, SpainE Moreno Gonzales; Hospital Central de Asturias, Oviedo, SpainD I Gonzalez Pinto; Hospital Clinic I Provincial de Barcelona, Barcelona, Spain-G Valdecasas; Hospital Clinico Universitario de Zaragoza, Zaragoza, Spain-T Serrano; Hospital Clínico Universitario Santiago de Compostela, La Coruna, Spain-E Varo; Hospital de Cruces, Baracaldo-Vizcaya, Spain-J O de Urbina; Hospital Gal de Santo Antonio, Porto, Portugal-M Amil; Hospital Gregorio Maranon, Madrid, Spain-C Kempin; Hospital Infantil Barcelona, Barcelona, Spain-C Margarit; Hospital Infantil La Paz, Madrid, SpainJ T Larrucea; Hospital Ntra Sra de Candelaria, Santa Cruz de Tenerife, Spain-A Soriano; Hospital Ramon y Cajal, Madrid, SpainE de Vicente Lopez; Hospital Regional "Carlos Haya”, Malaga, Spain-
A de la Fuente Perucho; Hospital "Virgen de la Arrixaca", El Palmar, Spain-F Sanchez Bueno; Hospital Universitario La Fe, Valencia, Spain-J Berenguer; Hospital "Marquès de Valdecilla", Santander, Spain-L A Herrera; Hospital Universitario "Reina Sofia”, Cordoba, Spain-C Pera; Hospital Universitario Virgen de la Nieves, Granada, Spain-D Ramia Angel; Hospital Universitario "Rio Hortega", Valladolid, Spain—G Sanchez Antolin; Hospital Virgen del Rocio, Sevilla, Spain-A Bernardos; Hôtel Dieu, CHU de Clermont-Ferrand, Clermont-Ferrand, France-J Chipponi; Huddinge Hospital, Huddinge, Sweden-B G Ericzon; I C C Bologna, Bologna, ItalyA D Pinna; Istituto di Chirurgia Generale I, Padova, Italy-A Maffei Faccioli; Instituto Mediterraneo per I Trapianti e Terapie ad alta Specializzione, Palermo, Italy-B Gridelli; Istituto Nazionale Tumori Milano, Milano, Italy_-V Mazzaferro; Johannes Gutenberg Univ Mainz Klinikum, Mainz, Germany-G Otto; King's College Hospital, London, UK-J G O'Grady; Klinikum der Christian Albrechts Univ, Kiel, Germany-B Kremer; Klinikum der J W Goethe Univ, Frankfurt am Main, Germany-W O Bechstein; Klinishe Abteilung für Transplantation, Wien, Austria-F Muhlbacher; Ludwig Maximilians Universität, Munchen, Germany-R Schauer; Medizinische Einrichtungen der Univ zu Köln, Köln, Germany-A Hölscher;

Medizinische Hochschule Hannover, Hannover, GermanyJ Klempnauer; Ospedale Cisanello, Pisa, Italy_F Filipponi; Ospedale Maggiore di Milano, Milano, Italy_L R Fassati; Ospedale NiguardaPizzamiglio II, Milano, Italy—L De carli; Ospedale San Eugenio “Tor Vergata”, Roma, Italy-G Casciani; Ospedali Riuniti di Bergamo, Bergamo, Italy-M Colledan; PET Centre, Aarhus, DenmarkS Keiding; Pomeranian Medical Academy, Szczecin, PolandR Kostyrka; Regina Elena Cancer Hospital, Roma, Italy-G Ettorre; Rigshospitalet, Copenhagen, Denmark-P Kirkegaard; Rikshospitalet, Oslo, Norway-I B Brekke; Royal Free Hospital, London, UKK Rolles; Royal Infirmary of Edinburgh, Edinburgh, UK-J Garden; Ruprecht-Karls-Univ Heidelberg, Heidelberg, Germany-E Klar; Sahlgrenska University Hospital, Göteborg, Sweden-S Friman; Semmelweis Medical University, Budapest, Hungary-F Perner; St Jame's and Seacroft University Hospital, Leeds, UK-S Pollard; St Vincent Hospital, Dublin, Ireland-O Traynor; Queen Elizabeth Hospital, Birmingham, UK-J Buckels; U C J Helsingfors, Helsinki, Finland-K Höckerstedt; Unidad de Transplante Hepatico, La Coruna, Spain—C Fernandez Sellez; Universita Cattolico del Sacro Cuore, Roma, Italy_M Castagneto; Universita Degli Studi di Roma, Roma, Italy-M Rossi; Universita di Genova, Genova, ItalyU Valente; Universitair Ziekenhuis, Ghent, BelgiumB de Hemptinne; Universitair Ziekenhuizen Leuven, Leuven, Belgium-J Pirenne; Universität Erlangen-Nürnberg, Erlangen, Germany-T Reck; Universität Leipzig, Leipzig, Germany-J Hauss; Universität Regensburg, Regensburg, Germany-K W Jauch; Universität Rostock, Rostock, Germany-W Schareck;

Universitätskrankenhaus Eppendorf, Hamburg, Germany-X Rogiers; Universitatspital Zurich, Zurich, Switzerland-P A Clavien; Universitatspital Bern, Bern, Switzerland-D Candinas; University Hospital, Udine, Italy_F Bresadola; University Hospital Gröningen, Gröningen, Netherlands-M J H Slooff; University Hospital Leiden, Leiden, Netherlands-O T Terpstra; University of Medicine "Carol Davila”, Bucharest, Romania-I Popescu; University of Modena e Reggio Emilia, Modena, Italy_-G Gerunda; University of Padova, Padova, Italy_D F D'amico.

\section{Acknowledgments}

The ELTR is supported by grants from Novartis, Fujisawa, and Roche, and receives logistical support from Hôpital Paul Brousse (Assistance Publique, Hôpitaux de Paris, Paris, France)

\section{References}

1 Roques F, Michel P, Goldstone AR, et al. The logistic EUROSCORE. Eur Heart J 2003; 24: 881-82.

2 Lin HM, Kauffman HM, McBridge MA, et al. Center-specific graft and patient survival rates: 1997 United Network for Organ Sharing (UNOS) report. JAMA 1998; 280: 1153-60.

3 Belle SH, Detre KM, Beringer KC. The relationship between outcome of liver transplantation and experience in new centres. Liver Transpl Surgery 1995; 6: 347-53. 
4 Ghobrial RM, Gornbein J, Steadman R, et al. Pre-transplant model to predict post transplant survival in liver transplant patients. Ann Surg 2002; 236: 315-23.

5 Bilbao I, Armadans L, Lazaro JL, Hildago E, Castells L, Margarit C. Predictive factors for early mortality following liver transplantation. Clin Transplant 2003; 17: 401-11.

6 Thuluvath PJ, Yoo HY, Thompson RE. A model to predict surviva at one month, one year, and five years after liver transplantation based on pretransplant clinical characteristics. Liver Transpl 2003; 9: $527-32$

7 Clavien PA, Camargo CA, Croxford R, Langer B, Levy GA, Greig PD. Definition and classification of negative outcomes in solid organ transplantation: application in liver transplantation. Ann Surg 1994; 220: 109-20.

8 Adam R, Cailliez V, Majno P, et al. Normalised intrinsic mortality risk in liver transplantation: European Liver Transplant Registry Study. Lancet 2000; 356: 621-27.

9 Adam R, McMaster P, O'Grady J, et al. Evolution of liver transplantation in europe: report of the European Liver Transplant Registry. Liver Transpl 2003; 9: 1231-43.

10 Karam V, Gunson B, Roggen F, et al. Quality control of the European Liver Transplant Registry: results of audit visits to the contributing centres. Transplantation 2003; 75: 2167-73.

11 Harrell FE, Lee KL, Mark DB. Multivariable prognostic models: issues in developing models, evaluating assumptions and adequacy, and measuring and reducing errors. Stat Med 1996; 15: 361-87.

12 Hosmer DW, Hosmer T, Le Cessie S, Lemeshow S. A comparison of goodness-of-fit tests for the logistic regression model. Stat Med 1997; 16: 965-80.
13 Adam R, Lucidi V, Karam V. Liver transplantation in Europe: is there a room for improvement? J Hepatol 2005; 42: 33-40.

14 Ascher NL, Lake JR, Emond JC, Roberts JP. Liver transplantation for fulminant hepatic failure. Arch Surg 1993; 128: 677-82.

15 Farmer DG, Anselmo DM, Ghobrial RM, et al. Liver transplanation for fulminant hepatic failure: experience with more than 200 patients over a 17 year period. Ann Surg 2003; 237: 666-75.

16 Kalayoglu M, Sollinger HW, Stratta RJ, et al. Extended preservation of the liver for clinical transplantation. Lancet 1988; 1: 617-19.

17 Adam R, Bismuth H, Diamond T, et al. Effect of extended cold ischaemia with UW solution on graft function after liver transplantation. Lancet 1992; 340: 1373-76.

18 Rela M, Vougas V, Muiesan P et al. Split liver transplantation: Kings College Hospital experience. Ann Surg 1998; 227: 282-88.

19 Bleeker SE, Moll HA, Steyerberg EW, et al. External validation is necessary in prediction research. J Clin Epidemiol 2003; 56: 826-32.

20 Jacob M, Copley LP, Lewsey JD, et al. Pretransplant MELD score and post liver transplantation survival in the UK and Ireland. Liver Transpl 2004; 10: 903-07.

21 Northup PG, Berg CL. Pre-operative delta MELD score does not independent predict mortality after liver transplantation. Am J Transplant 2004; 4: 1643-49.

22 Marino IR, Doria C, Doyle HR, Gayowski TJ. Matching donors and recipients. Liver Transpl Surgery 1998; 4: 5115-19. 